\title{
Review on Prevalence, Distrbution and Economic Significance of Liver Fluke in Ethiopia
}

\author{
Umer Seid ${ }^{1,}$,"Mulugeta Melese ${ }^{2}$ \\ ${ }^{I}$ Oda Bultum University, Collage of Agriculture, Department of Animal Science, Chiro, Ethiopia \\ ${ }^{2}$ Hadiya Zone AnilemoWoreda, Animal and Fishery Resource Department, Animal Health worker process \\ Coordinator
}

*Corresponding Author:UmerSeid, OdaBultum University, Collage of Agriculture, Department of Animal Science, Chiro, Ethiopia.Email:Omerseid76@gmail.com

\begin{abstract}
Fasciolosis is one of the most prevalent helminthic infections of ruminants in different parts of the world including Ethiopia. Liver fluke/Fascioliasis is an important trematode infection of cattle and sheep. It is caused by two members of genus Fasciola; Fasciola (F.) gigantica and F. hepatica. Fasciolosis is also known as, fasciolasis, distomatosis and liver rot. It occasionally affects humans, hence considered as a zoonotic disease.

Fluke transmission depends on the presence of snail that acts as intermediate host. It has great proliferation powers due to its large colonization capacities in its ruminant host and vector species. Human fascioliasis is commonly characterized by a hypo-endemic pattern, with low and stable levels of prevalence among a defined population and generally shows a focal endemic distribution. Snail vectors and distribution of fascioliasis in Africa (distribution of the F. hepatica and F.gigantica parasites) is ubiquitous, mainly attributed to, and associated with the equally global distribution of the viable, intermediate fresh-water snail hosts. Animal fasciolosis causes significant disease among sheep and cattle, causing severe physical wasting. It is widespread ruminant health problems and causes significant economic losses to the livestock industry, which is caused by Trematode of the genus Fasciola that migrate in the hepatic parenchyma, and establish and develop in the bile ducts.

Disease of livestock have many additional direct and indirect impacts on human nutrition, community development and socio-cultural and also reduction in farm income, contributing to food insecurity and poor nutrition To control liver fluke fencing off wet areas, attending to leaking troughs and pipes, drainage or even consider housing early.
\end{abstract}

Keywords: Fasciolosis, Ethiopia, Snail vectors, disease

\section{INTRODUCTION}

Liver fluke infection caused by Fasciola hepatica and F.gigantica remains economically significant parasite of livestock and is emerging zoonotic infection. It causes morbidity and mortality in most mammalian species and by far important in sheep and cattle $(\operatorname{Hod}++\mathrm{i}-\mathrm{c}$ e et al., 2013). A study conducted by (Keyyu et al., 2006), reported up to $100 \%$ liver condemnation rates in slaughter slabs in Iringa region in Tanzania in cattle. In Ethiopia the prevalence of fasciolosis is as high as $83.08 \%$ in cattle, $62.7 \%$ in sheep and $17.2 \%$ in goats.

The variation in climate-ecological conditions such as altitude, rainfall and temperature, and livestock management system influences the prevalence of fasciolosis together with survival and distribution of the parasites as well as their intermediate host (snails)(Kitila and Megerssa, 2015).

Fascioliasis, or liver fluke is a human and an animal parasitic disease caused by endoparasitic trematodes of the genus Fasciola which live in the bile ducts. Fasciola hepatica and F.gigantica are the most common species of liver flukes that cause hepatobiliary system infection mainly in cattle and sheep that they have an impact on public health. It has been stated by that $\mathrm{F}$. gigantica is responsible for the liver fluke in tropical areas, whereas F. hepatica is found more commonly in temperate climates. F. gigantica is restricted to Asia and Africa, however, F. hepatica has been found globally. Human fascioliasis is caused by F. hepatica as it is recently been recognized as an emerging and re-emerging zoonotic disease in several 
countries. Approximately, 17 million people have been infected and 180 million people at risk all over the world.

Most of the infected or at risk populations are in the USA, parts of Europe, South Africa, the Middle East and Asia. The reservoir hosts are mainly ruminants including cattle, sheep, goats, alpacas and deer but pigs and humans can be infected(Hardi et al., 2016)

Bovine fasciolosis is a parasitic disease of cattle caused by trematodes usually Fasciolagigantica and Fasciola hepatica in the tropics. The members of this genus are commonly known as liver flukes. The life cycle of these trematodes involves snail as an intermediate host (IH). The disease is found in vast water lodged and marshy grazing field condition anticipated to be ideal for the propagation and maintenance of high prevalence of fasciolosis. This disease is widely distributed in areas where cattle are raised and there is a niche for Lymnaeid snail. The disease is usually characterized by a chronic, sometimes acute or sub-acute inflammation of the liver and bile ducts, accompanied by sub-mandibular oedema, anemia, anorexia, general intoxication and death. It is an important limiting factor for bovine production. It causes several economic losses. The losses may be direct or indirect. The flukes cause severe liver damage and result in total condemnation of liver.

Diagnosis of bovine fasciolosis is based on clinical sign, grazing history, seasonal occurrence, examination of faces by laboratory tests and post-mortem examination. In cattle, chronic form of the disease is more common and drugs like rafoxanide and nitroxynil other than triclabendazole are more effective. The disease can be controlled by reducing the population of the intermediate host or by using anthelmintic(Admassu et al., 2015).

Fasciolosis is one of the most prevalent helminthic infections of ruminants in different parts of the world including Ethiopia. It causes significant morbidity and mortality. The prevalence and economic significance of fasciolosis in Ethiopia has been reported by several researchers. In recent years, small scale traditional irrigation schemes have been expanding in many parts of Ethiopia. Implementation of irrigated agriculture will create favorable habitat for fluke and snail vectors, thereby, influencing the occurrence of fasciolosis. Both F. hepatica and F. gigantica are found in Ethiopia and are transmitted by
Lymnaeatruncatula and L. natalensis, respectively(Yitagezuet al., 2015a).

In Ethiopia F. gigantica is found at altitude below 1800 masl. While F. hepatica is found at altitude between 1200-2560 masl. Mixed infection by both species of Fasciola may occur where the ecology is conducive for replication of both intermediate hosts. The snails of genus Lymnaea are mainly involved as an intermediate host in the life cycle of Fasciola. Lymnaeatruncatula is the most common intermediate host for F. hepatica in different parts of the world. The most important intermediate host for F. gigantica is L. natalensis and L. auriallaria.

The economic impact of Fasciolosis may vary greatly from year to year depending on the climate, management, level of infection, host immunity status and the age of animals. Ovine Fasciolosis losses were estimated at 48.4 million Ethiopian birr per year of which $46.5 \%, 48.8 \%$ and $4.7 \%$ were due to mortality, productivity (weight loss and reproductive wastage) and liver condemnation respectively. In Ethiopia, Fasciolosis is mainly an animal disease, causing a great economic burden in the highland areas of the country (Nyindo and Lukambagire, 2015; Ortiz et al., 2013; Yitagezu et al., 2015a).

Therefore, the objectives of this review are:

* To review aboutfasciolosis/liver fluke in Ethiopia

* To provide some information about epidemiology, treatment and control of the diseasein Ethiopia

* To provide some information on Prevalence, distribution and economic significance of liver fluke in Ethiopia

\section{BACKGROUND}

Liver fluke/Fascioliasis is an important trematode infection of cattle and sheep. It is caused by two members of genus Fasciola; Fasciola (F.) gigantica and F. hepatica. Genus Fasciola belongs to class Trematoda of the phylum Platyhelminthes. Class Trematoda is divided into two subclasses; Digenea and Aspidogastrea. Fascioliasis causes acute as well as chronic diseases. The disease has zoonotic importance and WHO has included it in list of neglected tropical diseases.

Liver fluke infection caused by Fasciola hepatica and F.gigantica remains economically significant parasite of livestock and is emerging 
zoonotic infection. Millions of human population is infected with fascioliasis and about 180 million are at risk of fascioliasis according to WHO estimation. Its prevalence is growing in human population and has been reported from 70 different countries of world(Nyindo and Lukambagire, 2015).

Fasciolosis is also known as, fasciolasis, distomatosis and liver rot. Fasciolosis is a parasitic disease of sheep, goat and cattle. It occasionally affects humans, hence considered as a zoonotic disease. They are responsible for wide spread morbidity and mortality in cattle characterized by weight loss, anemia and hypoproteinemia. Etiology-Fasciolosis is caused by different species of trematodes (commonly called "flukes") of the genus Fasciola. The taxonomic classification of the organisms that cause fasciolosis is presented as follows: Phylum: Platyhelminthes, Class: Trematoda, Sub class: Digenea, Order: Echinostomida, Super family: Fascioloidea, Genus: Fasciola, Species: F. hepatica and F. gigantica.

Morphology- Fasciola hepatica is a leaf shaped, fluke with broad and cone shaped anterior projection. It is grayish brown in color changing to gray when preserved. The tegument is armed with sharp spines. The young fluke at the time of entry in to the liver is 1-2 millimeter ( $\mathrm{mm}$ ) in length and lancet like when it has become fully mature in the bile ducts. It is leaf-shaped gray brown in color and is around $3.5 \mathrm{~cm}$ in length and $1 \mathrm{~cm}$ in width. The eggs of $F$. hepatica are oval in shape, brownish or yellowish brown in color. The eggs have an indistinct operculum and develop only after the eggs have been laid. Fasciola eggs should be distinguished from the eggs of other flukes, especially from the large eggs of paramphistomum. Fasciola eggs have yellowish brown shell with an indistinct operculum and embryonic cells where as paramphistomum eggs have transparent shell, distinct operculum with embryonic clear cells and possess a small knob at their posterior ends. F.gigantica is larger than F. hepatica and can reach up to $7.5 \mathrm{~cm}$ length. The shape is more of leaf like, the conical anterior end is very short and the shoulder characteristic of F. hepatica is barely perceptible. The eggs are larger than those of F. hepatica, measuring 190x100 micrometer $(\mu \mathrm{m})$ (Admassu et al., 2015).

\section{Current Status of Liver Fluke}

Fascioliasis is primarily a disease of ruminants, although over the past two decades humanfasciolosis has gained significance as an important disease in humans. Human fascioliasis is commonly characterized by a hypo-endemic pattern, with low and stable levels of prevalence among a defined population and generally shows a focal endemic distribution. However, to-date there have been reports from every continent except the Antarctica, thereby showing a wide cosmopolitan distribution(Nyindo and Lukambagire, 2015).

Despite the recent developments in diagnostic and surveillance techniques, some countries are still completely lacking in data on human fascioliasis. This may be because the disease is not endemic, but is more likely due to under reporting/ diagnosis especially in the resource limited settings. The underestimated global burden of the disease to date is approximated to be between 35 to 72 million people, with an additional 180 million at risk of infection. Abundant data supporting animal fasciola infections are available in many tropical developing countries and regions, with the corresponding presence of snail species responsible for transmission. Therefore the possibility of transmission of animal fascioliasis to humans is high where close proximity of humans with domestic animals is common(Nyindo and Lukambagire, 2015; Ortiz et al., 2013).

Although suitable environment and interactions for transmission have been established in many potentially endemic areas, reliable diagnostic and surveillance methods to establish presence of human fascioliasis are usually lacking. The apparent rarity of human fascioliasis infection in such areas underestimates the prevalence of the disease. Because local physicians may not be fully informed about human fascioliasis, they may mistake fascioliasis for other diseases with similar clinical picture(Nyindo and Lukambagire, 2015).

\section{ECOLOGY OF LIVER FLUKE}

Involvement of one or two intermediate hosts in life history is a characteristic of digeneans. Fluke transmission depends on the presence of snail that acts as intermediate host. Fascioliasis has great proliferation powers due to its large colonization capacities in its ruminant host and vector species. So the disease is limited to only those geographic areas where snail population is present. Areas with higher annual rainfall, poor drainage and certain type of soil that hold moisture are well suited to maintenance of 
disease and its propagation. Colonization of Fasciola in new environment and geographical area is mainly due to its adaption to a range of Lymnaed species. Both fasciolidae species are specific for their intermediate host that determines their distribution in environment. The intermediate host for $\mathrm{F}$. hepatica is more amphibious in nature and require little/very small water bodies, depending upon seasonal rainfall; whereas, Lymnaed responsible for $\mathrm{F}$. gigantica are in need of large, deep, permanent water bodies with rich in aquatic vegetation.

Different genera of snail which serve as intermediate host for F. hepatica and F. gigantica are Galba/Fossaria, Lymnaea and Radix, respectively.

The most common intermediate host for $\mathrm{F}$. hepatica is L. truncatula in different parts of the world and is prevalent in Europe, Asia, Africa and North America. L. bulimoidesis found in North America and L. tomentosa is in Australia while L. natalensis and $4 \mathrm{~L}$. auricularia act as intermediate hosts for F. gigantica. Fascioliasis in Asia and Africa is mainly caused by F. gigantica(Rehman et al., 2013).

\section{EPIDEMiOlogy OF LiVER FLUKe}

Snail vectors and distribution of fascioliasis in Africa (distribution of the F. hepatica and F.gigantica parasites) is ubiquitous, mainly attributed to, and associated with the equally global distribution of the viable, intermediate fresh-water snail hosts. Species distribution of the Lymnaeid snails may be generalized as mainly temperate, at a higher altitude over $2500 \mathrm{~m}$ above sea level for Lymnaeatruncatula, L. rubiginosa and their associated parasite, F. hepatica while $\mathrm{L}$. rupestris and $\mathrm{L}$. natalensis alongside their typical parasite F. gigantica have a more tropical/ sub-tropical distribution at lower altitudes, below $2000 \mathrm{~m}$.

In several countries in Africa and Asia it should be considered that F. hepatica and F. gigantica coexist, notably in areas of the Nile drainage, the great lakes mountain ranges and the rift valley arms. In such environments, alternating altitudes and climatic conditions favor the respective snail vectors. The differential specific diagnosis relating to eggs, and specific antigens is of interest because of their different transmission, epidemiology and control measures. Mixed infections and hybridization have also been cited recently. Surveys done in the hyper endemic Nile delta valley in Egypt and river Tana basin in Ethiopia found a high association between fascioliasis and schistosomiasis as well as myriad other intestinal parasites. The co-infection and childhood distribution raises a further differential in the clinical presentation and etiology of parasitic illnesses on the continent especially in rural, animal rearing areas. On the other hand, it is strange that no published studies or reports on the disease in humans have emerged from these potentially endemic regions(Nyindo and Lukambagire, 2015).

Factors noted to contribute to increased human transmission of fascioliasis include; (i) high density of both human and animal populations living in close proximity, (ii) the presence of abattoirs and wet markets operating with rudimentary hygiene, limited cold chain for distribution as well as low levels of meat inspection and bio-safety measures, (iii) widespread consumption of raw/undercooked blood, meat, organ tissues, offals and consumption of raw leaf vegetables (iv)the use untreated water sources for household use and/ or use of untreated wastewater and sewage for agriculture(Nyindo and Lukambagire, 2015)

\section{LIFE CYCLE OF LIVER FLUKE}

Knowledge of the life cycle of a parasite may contribute to control strategies focusing either on the mammalian host or the vector. Infected mammals including cattle, sheep, buffaloes, donkeys and pigs but also horses, goats, dromedaries, camels, llamas and other herbivores pass ovulated eggs in stool into fresh-water sources. Since the fasciola worm lives in the bile ducts of such animals, its unembryonated eggs reach the intestine with bile and are voided with feces. Fresh water is required for the development of intermediate stages of the fasciola species in the snail. The ciliated miracidium hatches from the egg. It bores a snail in the genus Lymnae and develops into a sporocyst. The next developmental stages are redia and cercaria which later vacate the snail.

The cercaria can infect the definitive mammalian host, including humans passively when the host drinks infected water or it can encyst on leaves and the mammalian host becomes infected when it eats leaves containing the metacercariae. The ingested metacercariaeexcyst in the duodenum and migrate into the peritoneal cavity and finally reach the liver. They bore through the liver 
capsule and in about 12 weeks enter the bile ducts where they start to lay eggs. Infected persons develop hyperplasia of the bile ducts. Clinically patients lose appetite, have nausea and diarrhea. Urticaria, acute epigastric pain, jaundice, eosinophilia and hepatomegaly are common findings. In the chronic phase of the disease hyperplasia of the gall bladder and biliary epithelium occurs and this leads to biliary tract obstruction. When live adult worms in an infected liver lodge in the throat region, they cause discomfort. After a period of about one to two months, a hypersensitivity reaction in the pharyngeal area develops. The term Halzoun syndrome describes the resulting suffocative immunological reaction at the pharyngeal area(Nyindo and Lukambagire, 2015).

Generally, Fasciola has two-host life cycle and comprises of four different phases. Adult flukes reside in bile duct of definitive host; eggs are passed onto the ground in feces. Transit period of egg development in water of appropriate physicochemical characteristics and temperature of 15-25o C usually take 2-3 weeks. Miracidium Figure2. Liver flukes utilize a definitive host (cattle or sheep) and an intermediate host (water snails) in their life cycle. hatch from egg and attempt to find an intermediate host (snail), which after penetrate in intermediate host, replicate asexually in to sporocyst, redial and cercarial form in snail, that takes approximately 5 to 7 weeks depending on temperature (if high temperature then this time is curtail) of environment. In wet conditions, these cercariae emerge and swim to vegetation where they encyst into metacercariae; this shedding process requires a temperature range of 9-26o C. Animals become infected by ingestion of these metacercariae that excyst, releasing juvenile flukes in small intestine. These juvenile flukes penetrate the wall of small intestine (duodenum), migrate through the peritoneal cavity over a period of 7 days and then penetrate through liver capsule. Juvenile flukes migrate through hepatic parenchyma for approximately 6 to 8 weeks before entering the bile ducts where they mature. Egg production begins as early as 8 weeks after infection. Thus the entire life cycle (egg shed to next generation egg shedding) is completed in 18-24 weeks (4.5 to 6 months)(Rehman et al., 2013).

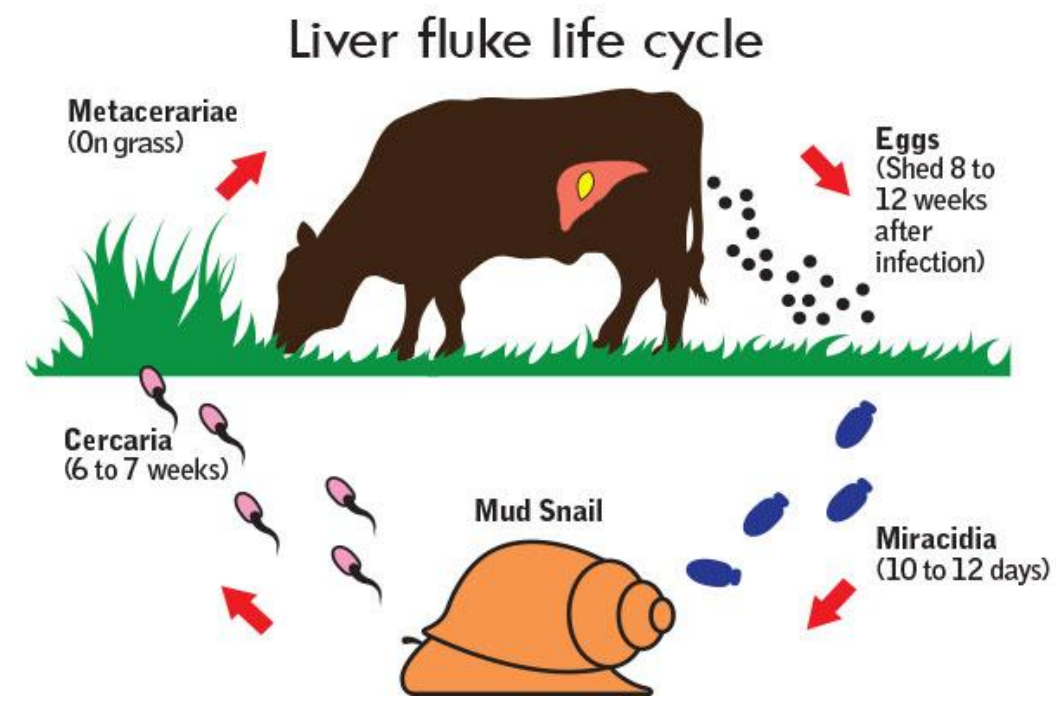

Source:farmer's weekly (from online course)

\section{Treatments}

A medication called triclabendazole is commonly used to treat a liver fluke infection, as this effectively kills the liver flukes and their eggs. Other drugs, such as pain relievers, may be used to treat some of the symptoms such as pain and diarrhea. Surgery may be necessary in rare cases where cholangitis, an infection of the bile ducts in the liver, has developed (https://www.medicalnewstoday.com/articles/31 9479.php).

\section{Control of Liver Fluke}

Identify high risk areas of fluke and consider if grazing these pastures in the late summer /autumn can be avoided. According to(Ortiz et al., 2013) the following points should be Practical tocontrol liver fluke. Steps include fencing off wet areas, attending to leaking troughs and pipes, drainage or even consider housing early.Ask for abattoir feedback on any liver rejections. This is a free and invaluable option for getting an early warning that there may be a fluke problem on a farm. Early action 
will minimize reduced performance due to subclinical liver fluke infections. Investigate losses in sheep if you have sheep on your farm, as this can be an indication of fluke risk for your cattle. Treat your cattle using the most appropriate drug, most suitable for time of year and management of cattle involved. Be sure to understand the product choices available in terms of the age or stage of liver fluke to be targeted because there are distinct differences in the effect of flukicides. Consider meat and milk withdrawal periods as well. Only use a combination product if appropriate - at housing for example, when fluke, lungworm and gut worms may all need to be controlled, but check with your vet or suitably qualified person (SQP) and make it part of your parasite control plan. Always treat effectively. Under-dosing is a major issue, leaving parasites alive in the animal which will cause damage to the liver and encourage resistance to develop. Weigh, don't guess, and be prepared to split cattle groups if there is a wide variation in live weight to ensure the dose rate is accurate.

Calibrate equipment regularly for all means of administration (drench, pour-on or injectable). If the product is orally administered ensure the drench is delivered over the back of the tongue. Follow the prescriber and manufacturer instructions for storage and administration accurately.Consider if you need to reduce pasture contamination levels in spring/summer by using a treatment with a drug that kills adult fluke to kill egg laying parasites. This should be based on individual risk factors and abattoir feedback. Remember to repeat the treatment if necessary. If you leave cattle on infected pasture after treatment you may need to re-treat them in six to 12 weeks depending on the product you use. None of the flukicidal products are persistent so animals can pick up infection straight away after treatment. Resistance to some flukicides is increasingly prevalent in sheep, so it is important to have an effective control plan for cattle that reduces the risk of resistance spreading. If you suspect resistance, arrange a drench test, i.e. A Faecal Egg Count Reduction Test (FECRT), with your vet/SQP.

Quarantine all incoming stock (sheep as well as cattle) from potential fluke areas for liver fluke as well as roundworms. This will take considerable planning but failure to do it could result in importing resistant liver fluke from another farm as well as losses and/or reduced performance in the animals themselves. Be
Prepared. Don't wait until the losses are mounting up. Act now to work with your vet or SQP to plan ahead in terms of management control options, treatments and monitoring that can be put in place. Treatment-Not all compounds are equally effective against all stages of development of F. hepatica in the body. For the treatment of acute fasciolosis, it is essential to choose a product which is highly effective against the juveniles that damage the liver parenchyma. For chronic disease a compound active against adult fluke is required. Triclabendazole $(12 \mathrm{mg} / \mathrm{kg})$ is considered as the most common drug due to its high efficacy against adult as well juvenile flukes. It is effective against adult $\mathrm{F}$. hepatica at a dose rate of $10 \mathrm{mg} / \mathrm{kg}$ in cattle. It is ovicidal and will kill any F. hepatica eggs present in the bile duct or the alimentary tract at the time of treatment(Admassu et al., 2015)

\section{ECONOMIC SIGNIFICANCE OF LIVER FLUKE}

Animal fasciolosis causes significant Disease among sheep and cattle, causing severe physical wasting. It contributes to losses of over $\$ 2$ billion dollars per annum in the livestock industry in north and South America. Human Fasciolosis also causes significant illness and morbidity, mainly among low income, farming communities. To date, no human deaths have been directly associated with fascioliasis. This fact accords the disease a low priority and contributes to its neglect as a significant cause of public health concern. Human fascioliasis is currently ranked under the food/ plant trematode zoonoses as a neglected tropical disease(Nyindo and Lukambagire, 2015)

The worldwide estimated loss caused by fasciolosis was more than US $\$ 2$ billion/year. It causes heavy losses to livestock industry by decreasing milk \& meat production, liver condemnation and cost of control. Single fluke has capacity to suck 0.2 to $0.5 \mathrm{ml}$ blood/animal leading to anemia, and lowering of total protein contents resulting in hypoalbuminemia(Rehman et al., 2013).

While chronic fascioliasis hampers the feed conversion ratio that ultimately leads to reduced growth rate and wool production. Fluke digests and causes necrosis of liver tissue leading to extensive parenchymal destruction and profound haemorrhagic lesions. Migrating juvenile flukes cause mechanical liver damage. Macerated hepatic cells have been observed inside the oral sucker and pharynx. Moreover, the process of 
ulceration of liver tissue was observed in regions 5 adjacent to the spiny body of fluke tegument. On the other hand, the injury of the liver can be induced chemically by factors produced or induced by the fluke. Probably, fluke proteases and other tissue-degrading enzymes can be responsible for negative effect on liver parenchyma. There is no evidence to link fluke-enzymes with tissue penetration.

The consequences of liver damage resulting from the migrating flukes compromises liver function which is reflected in changes of plasma protein concentration (albumin, globulin). Reproductive performance of livestock is affected by fascioliasis by reducing growth rate of young stocks, elevated puberty age of heifers and prolonged estrus intervals in adult animals (Ahmed et al., 2006). Simseket al. (2007) reported that among repeat breeder cows, $58.4 \%$ were seropositive to $F$. hepatica. Various researchers have estimated the economic losses conferred by fascioliasis.

Human fasciolosis has been reported from countries in Europe, America, Asia, Africa and Oceania. The incidence of human case has been increasing in the 51 countries of 5 continents. A person must ingest the metacercaria to become infected. Human acquire infection through ingestion of metacercaria that are attached to certain aquatic plant and vegetable. In addition experimental studies suggested that human consuming raw liver dish from liver infected with juvenile flukes could become infected. Economic loss in cattle, goat, buffalo and sheep. The disease causes considerable impact on the economy of the livestock industry. The economic losses consist of costs of anthelmintic, drenches, labor, liver condemnation at meat inspection; and losses in production due to mortality, reduction in meat, milk and reduction in growth rate, fertility and decreased feed intake, conversion and lower resistance to other disease(Admassu et al., 2015).

\section{Future Challenges of Liver Fluke}

The $21^{\text {st }}$ century has seen a dawning in the knowledge on human fascioliasis evidenced by the number of publications on the subject over the last 10 years. The complete implementation of this new knowledge and its translation into tangible results remains a challenge in the least developed countries (LDCs). Populations in LDCs are highest at risk of disease because of the following reasons; (i) poor access to this new body of knowledge, (ii) limited resources to put it into practical use, or (iii) have these limited resources dedicated to 'more threatening' problems than fascioliasis(Nyindo and Lukambagire, 2015; Ortiz et al., 2013).

The poverty-disease cycle is indeed a vicious, autocatalytic cascade. A typical complicating infection control scenario of zoonotic infections including fascioliasis in sub-Saharan Africa includes; a) global warming and civil unrest, b) close proximity to domestic animals, c) ruralurban migration with poor personal, water and food hygiene, and d) lax biosafety and surveillance systems. Therefore, control programs of human fascioliasis should have an integrated approach whereby all factors that contribute to the presence of the disease are considered. Cutting edge advances in diagnostic, surveillance and management techniques of fascioliasis have been made. Yet the developing countries and particularly the lowest income communities are not able to access these advances because of poverty. Heavily burdened by disease, civil unrest and competition for scarce resources, it is not surprising that there are hardly any reports on human fascioliasis from these regions. Control programs should first consider rigorous awareness campaigns and sensitization on both the magnitude and impact of human fascioliasis in humans and animals. The current 'One Health Integrated Global Approach to Disease' presents by far the most comprehensive and participatory solution, not only to human fascioliasis, but the bulk of zoonotic diseases at large. A classic example of the problems it tackles can best be elaborated in the recent drive to 'Go Green,' as a healthy approach to the modern artificial lifestyle(Hardi et al., 2016; Nyindo and Lukambagire, 2015; Ortiz et al., 2013).

Compartmentalized to specific sections like nutrition and preventive medicine, agriculture and industry, this has seen an unprecedented increase in the consumption of fresh, raw/ green fruit and vegetables. This is however poorly backed by water safety, fertilizer-pesticide use control, and waste management. The consumption of poorly monitored, produced and stored fresh green vegetables has contributed to the increased spread of plant food-borne trematodiases including fascioliasis, among many other health problems. Controlled clinical trials to investigate reported cases of Triclabendazole and Bithionol resistance of fasciola are areas of immediate research interest. Further development of chemotherapeutic options like the Myrrh-derived Mirazid and 
Nitazoxanide, as well as other novel interventions aimed at the intermediate snail hosts may provide much needed alternative chemotherapy(Nyindo and Lukambagire, 2015).

Control strategies aimed at the animal reservoirs and active surveillance for disease hotspots allow early intervention while improved food and water safety combined with possible vaccine development are vital to prevention strategies of human fascioliasis. In order to succeed all this needs to be backed by rigorous awareness, sensitization campaigns and political will to maximize uptake (Nyindo and Lukambagire, 2015; Ortiz et al., 2013; Yilma and Mesfin, 2000).

Human fascioliasis is perceived as a low significance "Neglected Tropical Disease of Poverty". As interventions and solutions to the disease are developed in the more developed countries/ communities, support structures, basic amenities and simple interdisciplinary collaborations degenerate equally fast in the lowest income communities at particularly high risk of infection. A case in point is observed in the abundance of veterinary reports on animal fascioliasis out of sub-Saharan African countries, countered by an almost total disregard for the human zoonoses among the medical and public health community. It is surprising that human fascioliasis is still not a reportable disease in many of these countries.

However, because of easy and fast global travel currently prevailing, open markets and free trade, cultural tourism and massive cultural and national integration, the problems of the developing countries may spill to more developed countries. The dawn of unpredictable climate changes and their effect on eco-biology, civil unrest and the simple natural laws of evolution are factors that have altered the patterns of spread of zoonoses. For example the recent global threat from the West African Ebola outbreak is a fresh reminder of the far reaching ramifications of unexpected disease outbreaks on the continent. Human fascioliasis is still non-fatal and results from interventions used in most hyper endemic regions prove that it can be effectively controlled, if not eradicated. As an NTD, this should be a tangible target(Nyindo and Lukambagire, 2015).

\section{Prevalence Of Liver Fluke in Different PARTS OF ETHiopia}

Table1.Provides review of a comprehensive data on the prevalence of fasciolosis in postmortem and cooprologicalexamination in different parts of the Ethiopia (2010-2018).

\begin{tabular}{|c|c|c|c|c|}
\hline No & Region & Species of parasite & Prevalence $/ \% /$ & References \\
\hline 1 & $\begin{array}{l}\text { Sheno municipal abattoir, } \\
\text { Oromia region }\end{array}$ & $\begin{array}{l}\text { Mixed(F.hepatica and } \\
\text { F.gingantica) }\end{array}$ & 74 & (Mekonnenetal.,2017) \\
\hline 2 & $\begin{array}{l}\text { Addis Ababa abattoir } \\
\text { enterprise, AA }\end{array}$ & Both & 18.75 & (Bayu et al., 2013) \\
\hline 3 & $\begin{array}{l}\text { Guduru and AbayChomaan } \\
\text { Districts }\end{array}$ & Both & 32.6 & (Daksa et al., 2016) \\
\hline 4 & $\begin{array}{l}\text { Addis Ababa Abattoir } \\
\text { Enterprise }\end{array}$ & Both & 18.8 & (Birhanu et al., 2015) \\
\hline 5 & $\begin{array}{l}\text { Areka municipal abattoir } \\
\text {,southern ethiopia }\end{array}$ & Both & 30 & (Moje et al., 2015) \\
\hline 6 & $\begin{array}{l}\text { Hawassa } \\
\text { abattoir, southern Ethiopia }\end{array}$ & Both & 28.63 & (Abebe et al., 2010) \\
\hline 7 & $\begin{array}{l}\text { Hossana Municipal abattoir, } \\
\text { Southern Ethiopia }\end{array}$ & Both & 30.5 & (Chakiso et al., 2014) \\
\hline 8 & $\begin{array}{l}\text { Woreta, Northwestern } \\
\text { Ethiopia }\end{array}$ & Both & 41.41 & (Tsegaye et al., 2012) \\
\hline 9 & $\begin{array}{l}\text { Addis Ababa Abattoir, } \\
\text { Ethiopia }\end{array}$ & Both & 20.3 & (Aragaw et al., 2012) \\
\hline 10 & $\begin{array}{l}\text { Dessie Municipal Abattoir, } \\
\text { South Wollo Zone, Ethiopia }\end{array}$ & Both & 25.2 & (Belay et al., 2012) \\
\hline 11 & Nekemte Municipal abattoir & Both & 21.9 & (Petros et al., 2013) \\
\hline 12 & $\begin{array}{l}\text { Hosanna Municipal } \\
\text { Abattoir, Southern Ethiopia }\end{array}$ & Both and mixed & 30.47 & (Betebo, 2017a) \\
\hline 13 & $\begin{array}{l}\text { Hosanna Municipal } \\
\text { Abattoir, Southern Ethiopia }\end{array}$ & Both & 30.47 & (Betebo, 2017b) \\
\hline 14 & $\begin{array}{l}\text { ELFORA Export Abattoir, } \\
\text { Bishoftu }\end{array}$ & Both & 21.13 & $\begin{array}{l}\text { (Kitila and Megerssa, } \\
\text { 2015) }\end{array}$ \\
\hline 15 & Livestock & Both & 60.42 & (Yeneneh et al., 2012) \\
\hline
\end{tabular}




\begin{tabular}{|c|c|c|c|c|}
\hline & $\begin{array}{l}\text { Research Center in north- } \\
\text { west of Ethiopia }\end{array}$ & & & \\
\hline 16 & $\begin{array}{l}\text { Kombolcha Industrial } \\
\text { Abattoir, Ethiopia }\end{array}$ & Both & 28 & (Ibrahim et al., 2010) \\
\hline 17 & bedele, ethiopia & Both & 32.53 & (Yitagezu et al., 2015b) \\
\hline
\end{tabular}

Table2.Review of Estimation of economic losses calculated by partially/totally condemned organs due tofasciolosis in different regions of Ethiopia (2010-2018).

\begin{tabular}{|l|l|l|}
\hline Name of the region /administrative city & Estimated economic loss/ETB & References \\
\hline Sheno municipal abattoir, Oromia region & $1,751,432$ annually & Mekonnen et al.,2017 \\
\hline Addis Ababa abattoir enterprise, AA & 157,684 annually & (Bayu et al., 2013) \\
\hline Areka municipal abattoir ,southern Ethiopia & $47,124 / 5$ month & (Moje et al., 2015) \\
\hline Hawassa Municipal abattoir, southern Ethiopia & $106,400 /$ annum & (Abebe t al., 2010) \\
\hline Hossana Municipal abattoir, Southern Ethiopia & $88,806.85 /$ annum & (Chakiso et al., 2014) \\
\hline $\begin{array}{l}\text { Dessie Municipal Abattoir, South Wollo Zone, } \\
\text { Ethiopia }\end{array}$ & 2,495,346.13/annum & (Belay et al., 2012) \\
\hline Nekemte Municipal abattoir & 63072/annum & (Petros et al., 2013) \\
\hline Kombolcha Industrial Abattoir, Ethiopia & 49491/annum & (Ibrahim et al., 2010) \\
\hline bedele, Ethiopia & 228,360.6/annum & (Yitagezu et al., 2015b) \\
\hline
\end{tabular}

\section{CONCLUSION}

In recent studies the last 8 years literature has been revised (2010-2017/18), from the revision of different literature the prevalence of liver fluke ranges from $14.84 \%-74 \%$ ( average $=44 \%$ ) as shown in the table. And the financial loss estimated from partial/total condemnation of the liver ranges from 47,124-2,495,346.13ETB/ annum. Even though there is Liver condemnation percentages in various slaughter house based on different studies, which was not mentioned in number. And the death of the human due to consumption of liver was not included in the study. The fact that human liver flukereporting in the developing nations is full of difficult challenge. Ethiopia is already heavily burdened by liver fluke/fasciolosis and lack access to adequate resources. Therefore, despite major progress in the diagnosis and control of human fascioliasis in the more developed countries, the disease continues to be a significant public health problem in Ethiopia. The breakdown of interdisciplinary collaborations, coupled by political and civil unrest further perpetuates the prevalence of liver fluke in Ethiopia. Fasciolosis is widespread ruminant health problems and causes significant economic losses to the livestock industry, which is caused by Trematode of the genus Fasciola that migrate in the hepatic parenchyma, and establish and develop in the bile ducts.

More over apart from its veterinary and economic importance throughout the country, Fasciolosis has recently been shown to be a reemerging and widespread zoonosis affecting many people. The average abattoir and cooprological examination prevalence of Fasciolosis in the present review in Ethiopia shows $44 \%$ which is higher than most other studies from different abattoirs in Ethiopia.

\section{RECOMMENDATIONS}

Liver fluke/fasciolosis continue to constrain, in a variety of different ways, livestock productivity, agricultural development, human well-being and poverty alleviation in many regions of the Ethiopia. The most important and read measurable direct effects of disease are often losses in productivity. These include the effects due to death, illness leading to condemnation, poor weight gain and poor feed conversion. Disease of livestock have many additional direct and indirect impacts on human nutrition, community development and sociocultural and also reduction in farm income, contributing to food insecurity and poor nutrition, therefore the control of the parasites based on the current review finding; the following points are recommended;

- Formulating functional meat inspection policies for organs and carcass approval/ rejection.

- Public education/awareness creation for farmers should be advocated

- Drafting appropriate policy to control illegal drug merchants and to avoid anthelmintic resistance

- Improving of the veterinary service and infrastructure

- general and clinical awareness

- Creating integrated and multidisciplinary collaborations between regions to control and prevent disease, since the disease are prevalent in almost all regions of Ethiopia. 
- Control of intermediate host snails through drainage Practicing zero grazing is important in the control of the disease

- Drainage of swampy area is also important in the reduction of the intermediate host

- Vaccine and drug development should be considered.

- Further epidemiological investigation should be encourage

\section{REFERENCES}

[1] Abebe, R., Abunna, F., Berhane, M., Mekuria, S., Megersa, B., Regassa, A., 2010. Fasciolosis: Prevalence, financial losses due to liver condemnation and evaluation of a simple sedimentation diagnostic technique in cattle slaughtered at Hawassa Municipal abattoir, southern Ethiopia. Ethiopian Veterinary Journal 14, 39-52.

[2] Admassu, B., Shite, A., Kinfe, G., 2015. A Review on Bovine Fasciolosis. European Journal of Biological Sciences 7, 139-146.

[3] Aragaw, K., Negus, Y., Denbarga, Y., Sheferaw, D., 2012. Fasciolosis in slaughtered cattle in Addis Ababa abattoir, Ethiopia. Global Veterinaria 8, 115-118.

[4] Bayu, Y., Asmelash, A., Zerom, K., Ayalew, T., 2013. Prevalence and economic importance of liver parasites: Hydatid Cyst, Fasciola species and Cysticercus tenuicolis in sheep and goats slaughtered at Addis Ababa abattoir enterprise in Ethiopia. Journal of Veterinary Medicine and Animal Health 5, 1-7.

[5] Belay, E., Molla, W., Amare, A., 2012. Prevalence and Economic Losses of Bovine Fasciolosis in Dessie Municipal Abattoir, South Wollo Zone, Ethiopia. Journal of Biological Sciences 4, 53-59.

[6] Betebo, T., 2017a. Prevalence of Fasciolosis in Cattle Slathered at Hosanna Municipal Abattoir, Southern Ethiopia. Int. J. Adv. Res. Biol. Sci 4, 70-76.

[7] Betebo, T., 2017b. Prevalence of Fasciolosis in Cattle Slathered at Hosanna Municipal Abattoir, Southern Ethiopia. Int. J. Adv. Res. Biol. Sci 4, 70-76.

[8] Birhanu, A., Tesfaye, R., Derso, S., 2015. Prevalence and Associated Risk Factors of Fasciola Infection in Small Ruminants Slaughtered at Addis Ababa Abattoir Enterprise, Ethiopia with Reference to Diagnostic Value of Its Coprological Examination. African Journal of Basic \& Applied Sciences 7, 181-186.
[9] Chakiso, B., Menkir, S., Desta, M., 2014. On Farm Study of Bovine Fasciolosis in Lemo District and its economic loss due to liver condemnation at Hossana Municipal abattoir, Southern Ethiopia. Int J Curr Microbiol Appl Sci 3, 1122-1132.

[10] Daksa, G., Abdisa, M., Desalegn, J., 2016. Abattoir Survey on Prevalence of Bovine Fasciolosis in Guduru and Abay Chomaan Districts. World Journal of Agricultural Sciences 12, 111-118.

[11] Hardi, F.M., Zana, M.R., Hawsar, O.M., 2016. Liver fluke (fascioliasis). International Journal of Applied Research 2, 265-271.

[12] Hod++i-ç, A., Zuko, A., Avdi-ç, R., Ali-ç, A., Omeragi-ç, J., Ja++i-ç, A., 2013. Influence of Fasciola hepatica on serum biochemical parameters and vascular and biliary system of sheep liver. Iranian journal of parasitology 8 , 92.

[13] Ibrahim, N., Wasihun, P., Tolosa, T., 2010. Prevalence of bovine fasciolosis and economic Importance due to liver condemnation at Kombolcha Industrial Abattoir, Ethiopia. Internet J Vet Med.

[14] Keyyu, J.D., Kassuku, A.A., Msalilwa, L.P., Monrad, J., Kyvsgaard, N.C., 2006. Crosssectional prevalence of helminth infections in cattle on traditional, small-scale and large-scale dairy farms in Iringa district, Tanzania. Veterinary research communications $30,45-55$.

[15] Kitila, D.B., Megerssa, Y.C., 2015. Pathological and serum biochemical study of liver fluke infection in ruminants slaughtered at ELFORA Export Abattoir, Bishoftu, Ethiopia. Global Journal of Medical Research.

[16] Moje, N., Mathewos, S., Desissa, F., Regassa, A., 2015. Cross-sectional study on bovine fasciolosis: prevalence, coprological, abattoir survey and financial loss due to liver condemnation at Areka Municipal Abattoir, Southern Ethiopia. Journal of Veterinary Medicine and Animal Health 7, 33-38.

[17] Nyindo, M., Lukambagire, A.H., 2015. Fascioliasis: an ongoing zoonotic trematode infection. BioMed research international 2015.

[18] Mekonnen, Y. and Mekonnen, A., 2003. Factors influencing the use of maternal healthcare services in Ethiopia. Journal of health, population and nutrition, pp.374-382.

[19] Ortiz, P., Scarcella, S., Cerna, C., Rosales, C., Cabrera, M., Guzm+ín, M., Lamenza, P., Solana, H., 2013. Resistance of Fasciola hepatica against Triclabendazole in cattle in Cajamarca (Peru): a clinical trial and an in vivo efficacy test in sheep. Veterinary parasitology 195, 118-121. 
[20] Petros, A., Kebede, A., Wolde, A., 2013. Prevalence and economic significance of bovine fasciolosis in Nekemte municipal abattoir. Journal of Veterinary Medicine and Animal Health 5, 202-205.

[21] Rehman, T.U., Khan, M.N., Sajid, M.S., Javed, M.T., 2013. slaughter house based epidemiology and estimation of economic losses of bovine fascioliasis in tehsil sargodha. Pakistan Journal of Science 65.

[22] Simsek, Z., Erol, N., Öztop, D., Münir, K., 2007. Prevalence and predictors of emotional and behavioral problems reported by teachers among institutionally reared children and adolescents in Tur

[23] Tsegaye, B., Abebaw, H., Girma, S., 2012. Study on coprological prevalence of bovine fasciolosis in and around Woreta, Northwestern Ethiopia. Journal of Veterinary Medicine and Animal Health 4, 89-92.
[24] Yeneneh, A., Kebede, H., Fentahun, T., Chanie, M., 2012. Prevalence of cattle flukes infection at Andassa Livestock Research Center in northwest of Ethiopia. Veterinary Research Forum. Faculty of Veterinary Medicine, Urmia University, Urmia, Iran, p. 85.

[25] Yilma, J.M., Mesfin, A., 2000. Dry season bovine fasciolosis in Northwestern part of Ethiopia. Revue de $\mathrm{m}+\neg$ decine $\mathrm{v}+\neg \mathrm{t}+\neg$ rinaire 151, 493-500.

[26] Yitagezu, A., Tefera, W., Mahendra, P., 2015a. Prevalence of bovine fasciolosis and its economic impact in Bedele, Ethiopia. Haryana Veterinarian 54, 7-10.

[27] Yitagezu, A., Tefera, W., Mahendra, P., 2015 b. Prvalence of bovine fasciolosis and its economic impact in Bedele, Ethiopia. Haryana Veterinarian 54, 7-10

Citation: UmerSeid, MulugetaMelese. Review on Prevalence, Distrbution and Economic Significance of Liver Fluke in Ethiopia. ARC Journal of Animal and Veterinary Sciences. 2018; 4(2):38-48. doi: dx.doi.org/ 10.20431/2455-2518.0402006.

Copyright: (C) 2018 Authors. This is an open-access article distributed under the terms of the Creative Commons Attribution License, which permits unrestricted use, distribution, and reproduction in any medium, provided the original author and source are credited. 